\title{
Erratum to: Using multistate capture-mark-recapture models to quantify effects of predation on age-specific survival and population growth in black-tailed deer
}

\author{
Lucile Marescot - Tavis D. Forrester • \\ David S. Casady • Heiko U. Wittmer
}

Published online: 9 December 2014

(C) The Society of Population Ecology and Springer Japan 2014

\section{Erratum to: Popul Ecol}

\section{DOI 10.1007/s10144-014-0456-z}

The original version of this article unfortunately contained two mistakes.

1. The percentages of 57 female deer $>1$ year old initially attributed to 3 distinct age classes have been reported incorrectly. The correct numbers are: yearlings $=5 \%$ $(n=3)$, prime-aged individuals aged 2-7 years $=77 \%$ $(n=44)$, and senescent individuals $=18 \%(n=10)$.
The online version of the original article can be found under doi:10.1007/s10144-014-0456-z.

L. Marescot - T. D. Forrester · H. U. Wittmer Department of Wildlife, Fish, and Conservation Biology, University of California Davis, One Shields Ave, Davis, CA 95616, USA

T. D. Forrester Smithsonian Conservation Biology Institute, National Zoological Park, 1500 Remount Rd, Front Royal, VA 22630, USA

D. S. Casady

California Department of Fish and Wildlife, Large Mammal Conservation Program, 1812 9th Street, Sacramento, CA 95811, USA

H. U. Wittmer ( $\square)$

School of Biological Sciences, Victoria University of Wellington, PO Box 600, Wellington 6140, New Zealand e-mail: heiko.wittmer@vuw.ac.nz
2. The total number of fawns that died during our study and their respective causes of mortality have been reported incorrectly. The correct numbers are: predation accounted for $67.5 \%$ of the 95 fawn mortalities we recorded (bears $=29, \quad$ coyotes $=20, \quad$ bobcats $=6, \quad$ pumas $=2$, unknown predators $=7)$. Malnutrition $(5.0 \%, n=5)$ and unknown causes other than predation and malnutrition (27.5\%,n=26) accounted for the remaining mortalities.

The authors sincerely apologize for these mistakes. 